\title{
Etilefrine Could Improve Response to Standard Medical Therapy in Chronic Hepatitis C Egyptian Patients with Cirrhotic Refractory Ascites: A Randomized Pilot Study
}

\author{
Ahmed M Ali ${ }^{*}$ and Thanaa G Awaad ${ }^{2}$ \\ ${ }^{1}$ Department of Clinical Pharmacy, Faculty of Pharmacy, Egypt \\ ${ }^{2}$ General Authority of Health Insurance, Cairo, Egypt
}

Submission: February 19, 2017; Published: June 27, 2017

"Corresponding author: : Ahmed M Ali, Department of Clinical Pharmacy, Faculty of Pharmacy, Central Axis, Part 1/1, Giza, Egypt, Tel: 20238354275; Email: ahmedzogary@yahoo.com

\begin{abstract}
Introduction: Ascites is a frequent complication of cirrhosis that accounts for over $75 \%$ of episodes of ascites. Patients with cirrhotic ascites have marked splanchnic vaso dilation and arterial hypotension with subsequent activation of vaso constrictive and anti-natriuretic mechanisms. One of the most serious complications in cirrhotic patients with ascites is the occurrence of refractoriness that is the inability to resolve ascites by the standard medical treatment. The aim of this study is to evaluate the effects of etilefrine on systemic hemo dynamics, renal function and control of ascites in chronic hepatitis $\mathrm{C}(\mathrm{CHC})$ patients with cirrhotic refractory ascites receiving standard medical treatment (SMT) with low sodium diet and maximal diuretic doses of $160 \mathrm{mg} /$ day of furosemide and $400 \mathrm{mg} / \mathrm{day}$ of spironolactone.
\end{abstract}

Methods: A total of $50 \mathrm{CHC}$ patients with cirrhotic refractory ascites were prospectively studied after 1 month administration of SMT $(\mathrm{n}=25)$ or SMT plus etilefrine $(\mathrm{n}=25)$, in a randomized controlled study.

Results: A significant increase in 24h urinary output, urinary sodium excretion, mean arterial pressure (MAP), and decrease in body weight, plasma renin activity and plasma aldosterone concentration $(\mathrm{P}<0.05)$ was noted after 1 month in the SMT/etilefrine group. Furthermore, the effective diuretic doses and the need for large-volume paracentesis were significantly reduced in the SMT/etilefrine group compared to the SMT group after 1 month of therapy. No significant changes in the aforementioned parameters were noted in the SMT group, except that MAP was significantly decreased. There was no significant change in the score of the model for end-stage liver disease (MELD) in the SMT/etilefrine group; however, there was significant deterioration in the MELD score in the SMT group.

Conclusion: These results suggest that the addition of etilefrine to SMT improves the systemic hemo dynamics and enhances water and sodium excretion, providing better control in patients with refractory cirrhotic ascites treated with SMT alone.

Keywords: Refractory ascites; Etilefrine; Systemic hemodynamics; Plasma renin activity; Renal function; Plasma aldosterone concentration Abbreviations: CHC: Chronic Hepatitis C; SMT: Standard Medical Therapy; MAP: Mean Arterial Blood Pressure; MELD: Model For End-Stage Liver Disease

\section{Introduction}

Ascites is the most common of the three major complications of cirrhosis; the other complications are hepatic encephalopathy and variceal hemorrhage [1]. Approximately $50 \%$ of patients with "compensated" cirrhosis develop ascites during 10 years of observation. Ascites is the most common complication of cirrhosis that leads to hospital admission [2]. Development of fluid retention in the setting of cirrhosis is an important landmark in the natural history of chronic liver disease: approximately $15 \%$ of patients with ascites succumb in 1 year and $44 \%$ succumb in 5 years [3]. Many patients are referred for liver transplantation after development of ascites. Refractory ascites develops in approximately $5-10 \%$ of all cases of cirrhosisrelated ascites and carries a high mortality rate [4]. The available therapies for patients with refractory ascites are repeated large volume paracentesis, transjugular intra hepatic portosystemic shunts, peritoneovenous shunts, and liver transplantation $[5,6]$. The mechanism by which refractory ascites develops in cirrhosis 
is related to splanchnic vasodilatation followed by maximal activation of the sympathetic nervous system (SNS) and the rennin-angiotensin- aldosterone system (RAAS) [7-10].

Splanchnic and peripheral vasoconstrictors (octreotide, midodrine and terlipressin) increase effective arterial volume and decrease activation of the renin-angiotensin system with resultant increase in renal sodium excretion [6]. Vasopressors causing splanchnic vasoconstriction have been used in hepatorenal syndrome [11-13] for the prevention of post-paracentesis circulatory dysfunction [14-16], improving circulatory and renal function in patients with cirrhotic ascites $[17,18]$ and for control of ascites in patients with refractory ascites [19]. Combined use of midodrine with standard medical therapy (SMT) was found to improve the systemic hemodynamics without any renal or hepatic dysfunction and is superior to SMT alone for the control of refractory cirrhotic ascites [20].

Clonidine, a centrally-acting presynaptic $\alpha 2$-adrenergic receptor agonist, when given with spironolactone has been shown to cause rapid mobilization of ascites by significantly decreasing the sympathetic activity and renin-aldosterone levels $[21,22]$. Synthetic vasopressin-V2 receptor antagonists are being evaluated for mobilization of ascites by increasing the excretion of solute-free water [23-25]. Etilefrine is a sympathomimetic agent with a potent stimulating effect on peripheral $\alpha$-adrenoceptors and a mild agonist effects on $\beta 1$ - and $\beta 2$ - adrenoceptors. It has a potent vasoconstrictor effect. It has a stimulant effect on the cardiovascular system where it raises blood pressure to normal, improves cardiac performance and tissue perfusion. Etilefrine is indicated in hypotension and, hypotensive circulatory disorders [26-28]. There are no published reports on the combined use of etilefrine and SMT in patients with refractory cirrhotic ascites. Therefore, this study is designed to investigate whether the longterm use of etilefrine would improve systemic hemodynamics and control of ascites in patients with cirrhosis and refractory ascites.

\section{Methods}

The study protocol was approved by the local ethics committee and was conducted in accordance with the principles of Helsinki declaration. Written informed consent was obtained from all patients before enrollment in the study. A total of 58 chronic hepatitis $C$ patients with refractory cirrhotic ascites were evaluated for inclusion in the study between November 2015 and May 2016. Eight of the enrolled patients were lost during the study period for different personal unidentified reasons. Accordingly, $50 \mathrm{CHC}$ patients with cirrhosis and refractory ascites with stable renal function (creatinine level $<1.5$ for at least 7 days), attending Gastroenterology and Hepatology Department of a specialized hospital were prospectively included in the study. Diagnosis of cirrhosis was based on clinical, biochemical and ultrasonographic findings with or without liver biopsy [29,30].

Inclusion criteria were as follows: presence of refractory ascites; patients less than 60 years of age and no treatment with drugs known to affect systemic or renal hemodynamics within one week before initiation of the study. Exclusion criteria were as follows: presence of marked hepatic encephalopathy, GIT bleeding, hepatorenal syndrome, hepatocellular carcinoma, bacterial peritonitis, portal vein thrombosis, arterial hypertension, diabetes, intrinsic renal or cardiovascular disease.

Refractory ascites is defined as

A. Fluid overload that is unresponsive to sodiumrestricted diet and high-dose diuretic treatment $(400 \mathrm{mg} / \mathrm{d}$ of spironolactone and $160 \mathrm{mg} / \mathrm{d}$ furosemide).

B. Buildup of fluid that recurs rapidly after therapeutic paracentesis or

C. Development of diuretic-related complications that exclude the use of an effective diuretic dosage [29].

Patients were randomized to either SMT alone $(n=25)$ or SMT plus oral etilefrine $(n=25)$. Etilefrine is active ingredient of Effortil ${ }^{\circledR}$ produced by Chemical Industries Development, Egypt under license of Boehringer Ingelheim International, Germany. Etilefrine was blindly given orally at a dose of $5 \mathrm{mg} / 8 \mathrm{~h}$. SMT was defined by dietary restriction of sodium $(\leq 2 \mathrm{~g} /$ day, starting at least 7 days before the start of the study), treatment with a combination of a loop diuretic (furosemide $160 \mathrm{mg} / \mathrm{d}$ ) and a distally-acting aldosterone antagonist (spironolactone $400 \mathrm{mg} / \mathrm{d}$ ) and repeated large volume paracentesis (LVP) along with intravenous albumin ( $8 \mathrm{~g} / \mathrm{L}$ of ascitic fluid removed). During the study period, diuretic doses were reduced by a 40 $\mathrm{mg}$ for furosemide and $10 \mathrm{mg}$ for spironolactone for a mean weight loss $>0.8 \mathrm{~kg}$ over 4 days from the previous weight. Largevolume paracentesis was performed when ascites is tense and symptomatic. Frequency of paracentesis sessions over the 4 weeks preceding the study was obtained from patient files. All patients were subjected to baseline clinical and biochemical workup including, body weight, mean arterial blood pressure, 24-h urinary output, 24-h urinary sodium excretion, liver function tests and renal function tests.

These parameters were assessed at baseline and at weekly intervals for 1 month. Measurement of mean arterial blood pressure (MAP) was calculated as diastolic blood pressure+((systolic blood pressure - diastolic blood pressure)/3). Three measurements were taken each 1-hour apart and the mean was calculated. Plasma renin activity and plasma aldosterone concentration were evaluated at baseline and after 1 month (endpoint). Plasma renin activity (PRA) was measured by radioimmunoassay using RIA plasma renin activity kit (Diasorin, Stillwater, MN, USA). Plasma aldosterone concentration (PAC) was measured by radioimmunoassay using ALDO-RIACT aldosterone kit (Cisbio, Parc Marcel Boiteux, France). Diuretic requirements were assessed at baseline, at weekly intervals and at endpoint. Patients were instructed to undergo tapping when become symptomatic. 


\section{Advanced Research in Gastroenterology \& Hepatology}

\section{Outcome Measures}

The primary endpoints of the study were partial or complete control of ascites. Complete response was defined as the elimination of ascites (as assessed by clinical examination and abdominal ultrasonography); a partial response was defined as the presence of ascites not requiring paracentesis; and absence of a response was defined as the persistence of ascites requiring paracentesis [31]. Secondary endpoints include alteration of diuretic requirements, changes in the scores of end-stage liver disease, liver and renal function, and frequency of other complications of cirrhosis (e.g., encephalopathy, upper GIT hemorrhage or development of hepatorenal syndrome) after 1 month of therapy.

\section{Statistical Analysis}

Data were analyzed using SPSS for MS-Windows (version 17.0, SPSS, Chicago, IL, USA). The baseline patient characteristics (clinical as well as biochemical) were compared between two groups (SMT or SMT plus etilefrine) by using Kruskal-Wallis ANOVA, Chi-square test or Fisher's exact test as appropriate. Intra-group comparisons were done using multiple repeatedmeasures analysis of variance. The paired t-test was performed to detect mean and standard deviation of prevalues (baseline) and postvalues (endpoint at 1 month) of the same variable of the same patients. The results were reported as mean values $\pm S D$. A p-value of $\leq 0.05$ was taken as significant.

\section{Results}

The demographic characteristics and baseline clinical and biochemical parameters were similar between SMT and SMT/ etilefrine groups (Table 1). Baseline body weight did not differ significantly between the two groups $(p>0.05)$. There was a significant decrease in mean body weight in SMT/etilefrine group at 1-month as compared to baseline $(\mathrm{p}<0.05)$ however; it did not change in the SMT group (Table 2) (Figure 1).

Table 1: Baseline clinical and biochemical variables of the two study groups.

\begin{tabular}{|c|c|c|}
\hline Variables & $\begin{array}{l}\text { SMT }(\mathrm{n}=25 ; \\
\text { group 1)* }\end{array}$ & $\begin{array}{c}\text { SMT+Etilefrine } \\
(\mathrm{n}=25 \text {; group } \\
2)^{*}\end{array}$ \\
\hline \multicolumn{3}{|c|}{ Gender } \\
\hline Male (\%) & $23(92)$ & $2(88)$ \\
\hline Female (\%) & $2(8)$ & $3(12)$ \\
\hline Age (years) & $48.86 \pm 9.17$ & $51.84 \pm 8.95$ \\
\hline Weight $(\mathrm{kg})$ & $75.82 \pm 13.44$ & $74.71 \pm 11.83$ \\
\hline MAP (mmHg) & $76.32 \pm 6.22$ & $74.95 \pm 5.78$ \\
\hline MELD score & $12.88 \pm 5.71$ & $12.95 \pm 3.89$ \\
\hline 24-h urine output (ml) & $651.8 \pm 263.71$ & $670.7 \pm 256.95$ \\
\hline $\begin{array}{l}\text { 24-h urinary sodium excretion } \\
\qquad(\mathrm{mEq} / \mathrm{l})\end{array}$ & $38.21 \pm 11.72$ & $37.62 \pm 13.32$ \\
\hline Plasma renin activity $(\mathrm{ng} / \mathrm{ml} / \mathrm{h})$ & $19.68 \pm 8.88$ & $20.72 \pm 9.27$ \\
\hline Plasma aldosterone conc. (pg/ml) & $1557.8 \pm 247.6$ & $1533.7 \pm 267.4$ \\
\hline Furosemide dose (mg/day) & $88.8 \pm 38.5$ & $94.3 \pm 40.4$ \\
\hline Spironolactone dose (mg/day) & $237.4 \pm 102.2$ & $249.2 \pm 106.6$ \\
\hline Rate of paracentesis $\geq 5 \mathrm{~L}$ & $1.14 \pm 0.79$ & $1.18 \pm 0.81$ \\
\hline \multicolumn{3}{|l|}{ (Times per one month) } \\
\hline Serum bilirubin $(\mathrm{mg} / \mathrm{dl})$ & $3.8 \pm 1.8$ & $4.1 \pm 2.2$ \\
\hline INR & $1.71 \pm 0.44$ & $1.62 \pm 0.26$ \\
\hline Serum creatinine $(\mathrm{mg} / \mathrm{dl})$ & $0.96 \pm 0.25$ & $1.10 \pm 0.22$ \\
\hline
\end{tabular}

SMT: Standard Medical Therapy; MAP: Mean Arterial Pressure MELD: Model for End-Stage Liver Disease; INR: International Normalized Ratio.

*Baseline values between groups 1 , and 2 are not significantly different $(P>0.05)$. Data are expressed as mean $\pm S D$.

Table 2: Clinical and biochemical parameters before and after 1 month of therapy.

\begin{tabular}{|c|c|c|c|c|}
\hline \multirow{2}{*}{ Variables } & \multicolumn{2}{|c|}{ SMT (n=25; group 1) } & \multicolumn{2}{c|}{ SMT+Etilefrine (n=25; group 2) } \\
\cline { 2 - 5 } & Prevalues (Baseline) & Postvalues (1 Month) & Postvalues (1 Month) & Prevalues (Baseline) \\
\hline Weight (kg) & $75.82 \pm 13.44$ & $76.56 \pm 10.61$ & $69.46 \pm 11.32^{*}$ & $74.71 \pm 11.83$ \\
\hline MAP (mmHg) & $76.32 \pm 6.22$ & $73.35 \pm 5.5^{*}$ & $83.7 \pm 6.45^{*}$ & $74.95 \pm 5.78$ \\
\hline MELD score & $12.88 \pm 5.71$ & $15.90 \pm 4.68^{*}$ & $12.64 \pm 4.1$ & $12.95 \pm 3.89$ \\
\hline 24-h urine output (ml) & $651.8 \pm 263.71$ & $672.3 \pm 266.86$ & $988.4 \pm 286.4^{*}$ & $670.7 \pm 256.95$ \\
\hline 24-h urinary sodium excretion (mEq/l) & $38.21 \pm 11.72$ & $40.22 \pm 10.58$ & $56.31 \pm 12.2^{*}$ & $37.62 \pm 13.32$ \\
\hline Plasma renin activity (ng/ml/h) & $19.68 \pm 8.88$ & $20.34 \pm 9.43$ & $14.21 \pm 7.56^{*}$ & $20.72 \pm 9.27$ \\
\hline Plasma aldosterone conc. (pg/ml) & $1557.8 \pm 247.6$ & $1529.5 \pm 298.2$ & $1140.5 \pm 312.6^{*}$ & $1533.7 \pm 267.4$ \\
\hline Serum bilirubin (mg/dl) & $3.8 \pm 1.8$ & $6.7 \pm 1.5^{*}$ & $3.9 \pm 1.6$ & $4.1 \pm 2.2$ \\
\hline INR & $1.51 \pm 0.42$ & $1.7 \pm 0.21^{*}$ & $1.53 \pm 0.28$ & $1.56 \pm 0.36$ \\
\hline Serum creatinine (mg/dl) & $0.96 \pm 0.25$ & $0.99 \pm 0.19$ & $1.00 \pm 0.3$ & $1.10 \pm 0.22$ \\
\hline Furosemide dose (mg/day) & $88.8 \pm 38.5$ & $96.0 \pm 44.6$ & $48.6 \pm 8.2^{*}$ & $94.3 \pm 40.4$ \\
\hline Spironolactone dose (mg/day) & $237.4 \pm 102.2$ & $256.0 \pm 115.3$ & $98.4 \pm 28.5^{*}$ & $249.2 \pm 106.6$ \\
\hline Rate of paracentesis $\geq 5$ L & $1.14 \pm 0.79$ & $1.22 \pm 0.72$ & $0.6 \pm 0.55^{*}$ & $1.18 \pm 0.81$ \\
\hline
\end{tabular}

SMT: Standard Medical Therapy; MAP: Mean Arterial Pressure; MELD: Model for End-Stage Liver Disease

*1-month values are significantly different from baseline $(P<0.05)$ in the etilefrine group but not in the SMT group. Data are expressed as 


\section{Advanced Research in Gastroenterology \& Hepatology}

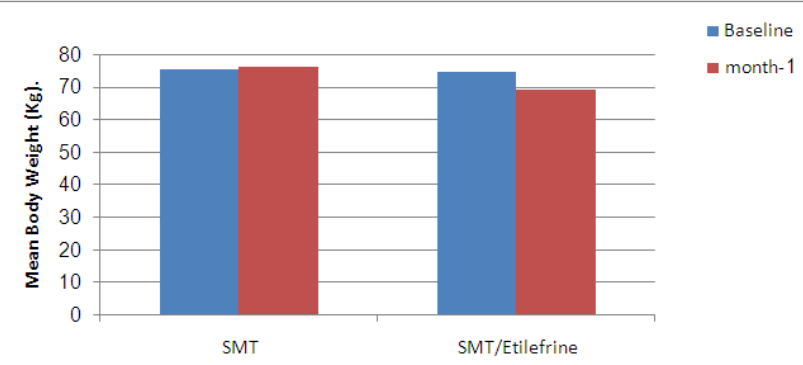

Figure 1: Mean body weight at baseline and after 1-month treatment with SMT and SMT/etilefrine. SMT, standard medical therapy.

Baseline MAP did not differ between SMT and SMT/etilefrine groups $(p>0.05)$. There was a significant increase in mean arterial pressure in SMT/etilefrine group at 1-month as compared to baseline $(\mathrm{p}<0.05)$ and a significant decrease $(\mathrm{p}<0.05)$ in the SMT group (Table 2) (Figure 2).

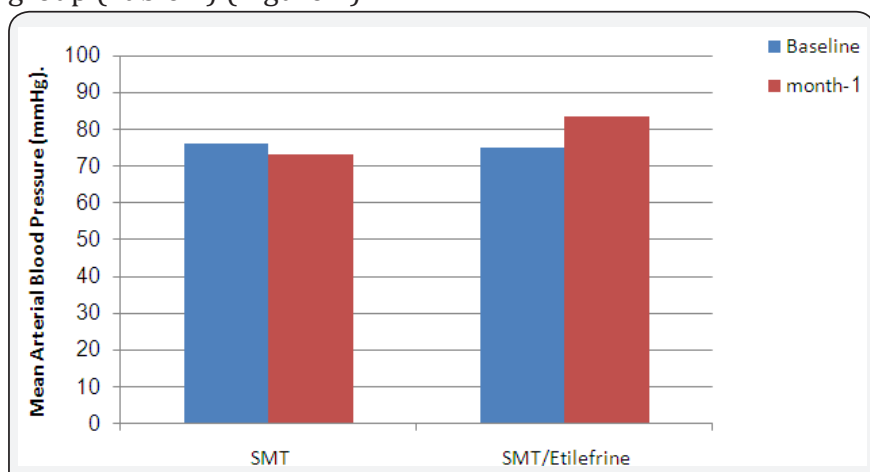

Figure2: Mean arterial blood pressure (MAP) at baseline and after 1-month treatment with SMT and SMT/etilefrine. SMT, standard medical therapy.

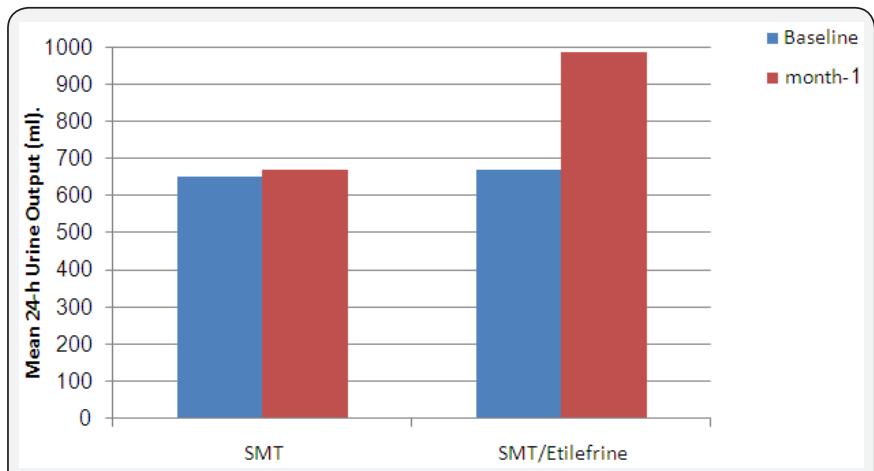

Figure 3: Mean 24-h urine output at baseline and after 1-month treatment with SMT and SMT/etilefrine. SMT, standard medical therapy.

Baseline urine output did not differ between SMT and etilefrine groups $(p>0.05)$. The urine output was significantly higher in the SMT/etilefrine group $(\mathrm{p}<0.05)$ but not the SMT after 1 month of treatment as compared to baseline (Table 2) (Figure 3).

Baseline urinary sodium excretion was comparable in the SMT and SMT/etilefrine groups $(p>0.05)$. Urinary sodium excretion significantly increased in the SMT/etilefrine group after treatment at 1 -month as compared to baseline $(\mathrm{p}<0.05)$; however, it did not change in the SMT group (Table 2) (Figure 4).

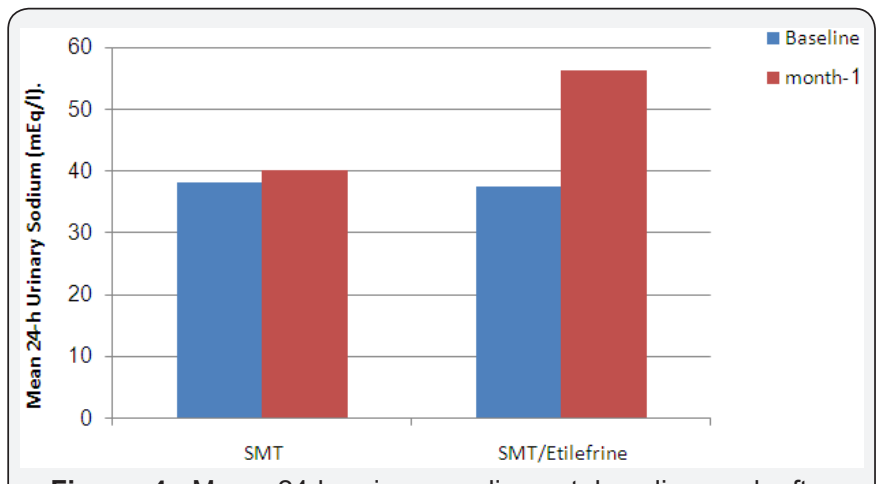

Figure 4: Mean 24-h urinary sodium at baseline and after 1-month treatment with SMT and SMT/etilefrine. SMT, standard medical therapy.

Baseline values for plasma renin activity (Table 1) were similar in both treatment groups ( $p>0.05)$. Plasma renin activity significantly decreased at 1 -month $(\mathrm{p}<0.05)$ only in the SMT/ etilefrine group with no change in the SMT group compared to baseline (Table 2) (Figure 5).

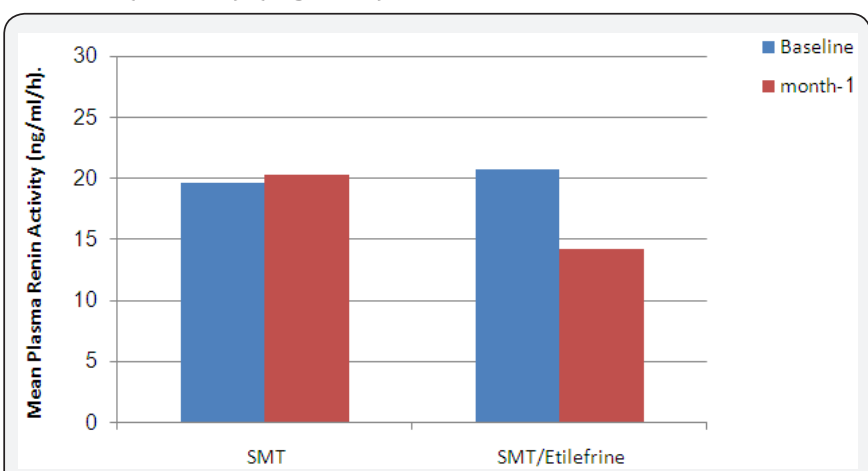

Figure 5: Mean plasma renin activity (PRA) at baseline and after 1-month treatment with SMT and SMT/etilefrine. SMT, standard medical therapy.

Baseline plasma aldosterone concentrations did not differ between the two groups $(p>0.05)$. Plasma aldosterone concentrations decreased significantly in the SMT/etilefrine group at 1 -month as compared to baseline $(\mathrm{p}<0.05)$; however, it did not change in the SMT group (Table 2) (Figure 6).

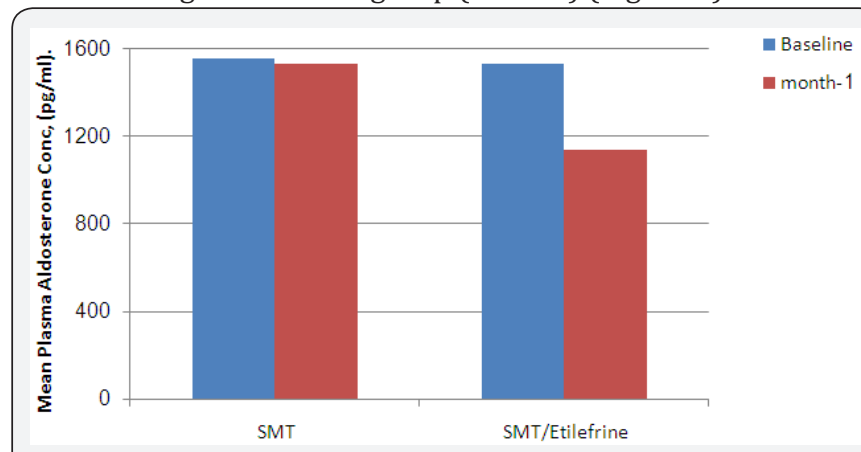

Figure 6: Mean plasma aldosterone conc. at baseline and after 1-month treatment with SMT and SMT/etilefrine. SMT, standard medical therapy.

Baseline values for serum creatinine in both SMT and SMT/ etilefrine groups were similar ( $p>0.05$, Table 1). There was no significant change in serum creatinine in both groups after 1-month treatment as compared to baseline ( $p>0.05$, Table 2). 
Baseline serum bilirubin and INR were similar in both groups ( $p>0.05$, Table 1 ) but there were significant increase in their values at 1 month only in the SMT group ( $p<0.05$, Table 2 ).

Baseline MELD score was similar in both treatment groups ( $p>0.05$; Table 1). There was a significant deterioration in MELD score in SMT group at 1 month $(\mathrm{p}<0.05)$ with no change in the SMT/etilefrine group as compared to baseline ( $p>0.05$; Table 2$)$.

The need for LVP ( $\geq 5 \mathrm{~L}$ ) was significantly reduced in the SMT/etilefrine group $\mathrm{p}<0.05$; (Figure 7) (Table 2) (at 1month compared to baseline value. No significant change was noted in the SMT group. Fifteen patients from the SMT group required LVP compared to only six in the SMT/etilefrine group over the 1-month period of therapy.

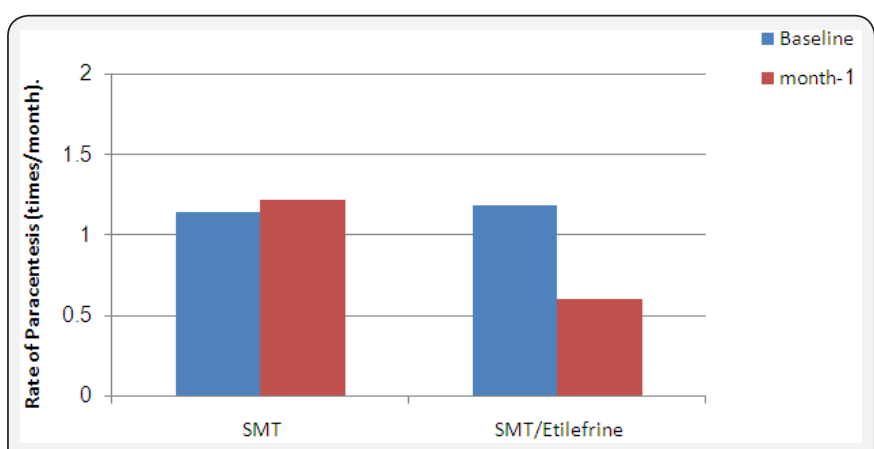

Figure 7: Rate of paracentesis $(\geq 5 \mathrm{~L})$ at baseline and after 1-month treatment with SMT and SMT/etilefrine. SMT, standard medical therapy.

As depicted in Table 2, diuretic requirements were significantly declined from baseline in the SMT/etilefrine group $(p<0.05)$ with no change in the SMT group.

There was higher rate of partial response to treatment and better control of ascites in the SMT/etilefrine group $\mathrm{p}<0.05$; (Table 3) (Figure 8) compared to SMT group at 1 month of treatment.

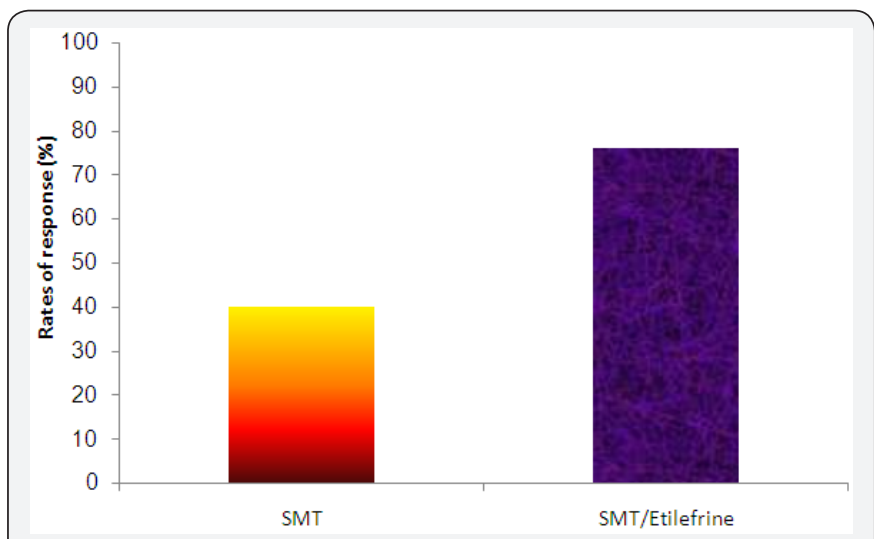

Figure 8: Rates of resonse (\%) and control of ascites after 1-month treatment with SMT and SMT/etilefrine. SMT, standard medical therapy.

Mild abdominal pain that subsided on its own was noted in three patients in the SMT group. In the SMT/etilefrine group, mild headache was developed in two patients, which disappeared with time without discontinuation of therapy.
Table 3: Rates of response in study groups after 1-month (expressed as number and percentage of patients).

\begin{tabular}{|c|c|c|}
\hline Response & SMT ( $\mathbf{n}=\mathbf{2 5}$; group 1) & $\begin{array}{c}\text { SMT+Etilefrine ( } \mathbf{n}=\mathbf{2 5} \\
\text { group 2) }\end{array}$ \\
\hline Partial & $10(40 \%)$ & $19(76 \%)$ \\
\hline No response & $15(60 \%)$ & $6(24 \%)$ \\
\hline
\end{tabular}

\section{SMT: Standard Medical Therapy}

\section{Follow-Up}

The 1-month morbidity and mortality of the study is depicted in (Table 4). In SMT group, encephalopathy developed in two patients, upper gastrointestinal bleeding, spontaneous bacterial peritonitis (SBP) and renal failure developed in one patient each. One case of SBP was recorded in the SMT/etilefrine group. The 1-month mortality was two in the SMT group and was related to sepsis during the follow-up period. No mortalities were recorded in the SMT/etilefrine group.

\section{Discussion}

Splanchnic arterial vasodilatation induced by nitric oxide [32] and glucagons [33] leads to disturbance of systemic hemodynamics reflected as reduced arterial blood pressure, reduced vascular resistance, and decreased effective blood volume with activation of potent vasoconstricting systems such as the sympathetic nervous system, the rennin angiotensin aldosterone system, in addition to nonosmotic release of vasopressin [34-36]. This results in renal vasoconstriction, avid sodium and fluid retention with development of ascites [37]. The administration of arterial vasoconstrictors has been associated with improvement in systemic hemodynamics and renal function in cirrhotic patients with ascites [38]. The efficacy of vasoconstrictors in advanced cirrhotic ascites might be related to failure of the activated endogenous vasopressor systems to counteract the arterial vasodilatation [39], probably due to reduced arterial reactivity to vasopressors [40]. Administration of intravenous arterial vasoconstrictors such as metaraminol [41], norepinephrine [42,43], angiotensin II [44] and terlipressin [45] in cirrhotic ascitic patients has been associated with improvement of systemic hemodynamics without harmful effects on renal function.

Midodrine, a potent peripherally acting oral $\alpha$-adrenergic receptor agonist, either alone $[19,20,46]$ or in combination with octreotide and albumin [47] has been used to improve renal hemodynamics in cirrhotic patients with ascites. In these studies, midodrine-induced splanchnic vasoconstriction improved systemic hemodynamics with better control of ascites without any renal or hepatic dysfunction.

Combined use of midodrine with tolvaptan, an aquaretic vasopressin V2 receptor antagonist, has been found to control ascites and improve response to diuretic therapy [48]. Rai et al. [48], reported that midodrine (by causing splanchnic vasoconstriction, increasing effective arterial blood volume and improving renal perfusion) and tolvaptan (by increasing free water clearance) acting at different sites in combination were 
more effective in combating increased renal sodium retention and refractoriness to diuretic therapy and better controlled ascites.

There are no studies in literature on the short- or long-term use of combination of etilefrine and standard medical therapy in patients with cirrhotic refractory ascites, therefore the results of the present study will be compared to previous studies in which different vasopressor agents were used for the control of refractory ascites.

In our study, we compared the changes in systemic hemodynamics (MAP), renal excretory function (24-hour urinary sodium excretion, 24-hour urinary output), plasma renin activity and plasma aldosterone concentration in patients with cirrhotic refractory ascites after 1-month treatment with SMT alone or in combination with etilefrine. Changes in models for end-stage liver disease scores, the need for paracentesis and diuretic requirements were also compared in both groups. In the current study, there was a significant increase in the mean arterial pressure (MAP) with etilefrine while there was no change in the SMT group. Etilefrine-induced increase in MAP may be related to reducing venous pooling and counteracting reflex arteriolar vasodilatation [28].

In agreement with our results, Kalambokis et al. [17,38] reported an improvement in circulatory function manifested as a significant increase in MAP after short-term use of midodrine [17] and chronic combined use of midodrine with octreotide [38] in patients with nonazotemic cirrhotic ascites. Similar results were reported after long-term use of midodrine with SMT [19,20,48] and combined use of midodrine with SMT and clonidine [20]. On contrary, Oda et al. [49] reported that a 3-month course of midodrine produced no change in MAP in cirrhotic patients with refractory ascites. In comparison to baseline values, our results showed a meaningful improvement in renal hemodynamics and function reflected as a significant increase in twenty-four-hour urine output and urinary sodium excretion in the etilefrine/SMT group but not in the SMT group. These findings agree with those observed with previous studies employing midodrine plus SMT $[19,20,48]$, combined use of midodrine with SMT and clonidine [20], and combined use of midodrine with SMT and tolvaptan [48]. In another study, a single dose of terlipressin (vasopressin V1 receptor agonist) showed marked increase in urinary sodium excretion in patients with and without refractory ascites [18]. The results of our study disagreed with a previous study [50] that found no change in 24-h urine volume after two-week midodrine therapy.

In the present study a significant decrease in plasma renin activity (PRA) and plasma aldosterone concentration was noted only in the etilefrine/SMT group after one-month therapy compared to baseline. This effect is possibly related to etilefrine-induced suppression of the renin-angiotensinaldosterone system. Similar results with other vasoconstrictors were reported by Singh et al. [19, 20] and Rai et al. [48] after long-term use of SMT/midodrine regimen [19,20,48], combined SMT/midodrine/clonidine therapy [20] or combined SMT/ midodrine/tolvaptan therapy [48]. In an earlier study, no change in PRA was noted in patients with refractory ascites maintained on a 3-month course of midodrine therapy [49]. In the current study, significant reduction in mean body weight was observed in patients receiving etilefrine plus SMT compared to those treated with SMT alone. This comes in concordance with previous findings of decreased body weight by midodrine $[38,50]$.

The reduction in body weight may be related to a drop in fluid accumulation by etilefrine-induced vasoconstriction with reflex inactivation of the renin-angiotensin-aldosterone system (RAAS). Similar explanation were reported in previous studies in which the authors observed a sig-nificant reduction in plasma renin and aldosterone concentration and a trend toward a reduction in the volume of ascitic fluid removed by paracentesis following the administration of midodrine $[38,50]$. No change in body weight was reported in a number of previous studies utilizing different vasoconstrictors including midodrine $[19,20,48]$. Rate of response to treatment, measured as need for large-volume paracentesis $(\geq 5 \mathrm{~L})$ and reduction of ascites with SMT alone or combined SM/etilefrine therapy was measured.

There was higher rate of response to treatment, reflected as a significant decrease in the number of times of paracentesis in the combined SM/etilefrine therapy at 1 month. There was no significant change in rate of response to treatment in the SMT group. These results come in harmony with some previous studies in which the vasoconstrictor midodrine was used with various daily doses $[20,48,50]$. In another study, midodrine along with octreotide and albumin given for 1 month showed lesser requirement of paracentesis in eight patients with refractory ascites [47]. In agreement with previous studies evaluating midodrine $[17,19,20,48]$, midodrine and clonidine [20], midodrine plus octreotide [38] or midodrine plus tolvaptan [48] in cirrhotic patients with ascites, our results did not show significant change in hepatic function or MELD score in the combined SMT/etilefrine group. A significant deterioration in MELD score was noted in the SMT group at 1 month.

In one previous study [38], combined use of SMT with midodrine and tolvaptan showed significant improvement in MELD score at 1 and 3 month of therapy. In another pilot study, significant deterioration in the MELD score was observed during treatment with midodrine at 1 month of therapy [47]. Diuretic needs for furosemide and spironolactone were significantly reduced in the SMT/etilefrine group at 1 month compared to baseline. Diuretic doses were reduced by increments of $40 \mathrm{mg}$ (furosemide) $/ 100 \mathrm{mg}$ (spironolactone) for each $\geq 0.8 \mathrm{~kg}$ mean decrease in body weight from the previous weight over 4 days of therapy according to the criteria of International Ascites Club [51]. The reduction of diuretic requirements and subsequent enhancement in diuretic response may be related to etilefrineinduced improvement in renal perfusion and/or its inhibitory 
effect on RAAS. No significant change in diuretic needs was noted in patients receiving SMT alone. Reduction in diuretic needs with better control of ascites was reported in one earlier pilot study [20]. There was higher rate of partial response to treatment (defined as ascites requiring no paracentesis) and better control of ascites in the SMT/etilefrine group compared to SMT group at 1 month of treatment (76 versus $40 \%$ ). Etilefrine use was well tolerated by the majority of patients. Only two patients developed mild headache that resolved spontaneously within few days without discontinuation of treatment.

\section{Conclusion}

To our knowledge, this is the first study of long-term use of combined SMT/etilefrine therapy in patients with cirrhotic refractory ascites. In patients receiving combined SMT/ etilefrine therapy, we observed a significant increase in MAP, 24-h urinary output, 24-h urinary sodium excretion and a significant reduction in body weight, plasma renin activity and aldosterone concentration. There was a considerable reduction in the need for large volume paracentesis and diuretic therapy. Large multicentre, randomized-controlled trials are required before combined SMT/etilefrine therapy can be routinely recommended.

\section{Acknowledgement}

The authors thank Mrs. Olfat M. Ali, Saridar Laboratories, Cairo, Egypt for her great help in the biochemical analysis of the studied parameters.

\section{References}

1. Pant D, Singh A, Van Bogaert G, Olsen SI, Nigam PS, et al. (2012) Bioelectrochemical systems (BES) for sustainable energy production and product recovery from organic wastes and industrial wastewaters. RSC Adv 2(4): 1248-1263.

2. Clauwaert P, Van der Ha D, Boon N, Verbeken K, Verhaege M, et al. (2007) Open air biocathode enables effective electricity generation with microbial fuel cells. Environ Sci Technol 41(21): 7564-7569.

3. Rozendal RA, Hamelers HV, Euverink GJ, Metz SJ, Buisman CJ (2006) Principle and perspectives of hydrogen production through biocatalyzed electrolysis. Int J Hydrogen Energy 31(12): 1632-1640.

4. Aulenta F, Canosa A, Majone M, Panero S, Reale P, et al. (2008) Trichloroethenedechlorination and $\mathrm{H} 2$ evolution are alternative biological pathways of electric charge utilization by a dechlorinating culture in a bioelectrochemical system. Environ Sci Technol 42(16): 6185-6190.

5. Aulenta F, Canosa A, Reale P, Rossetti S, Panero S, et al. (2009) Microbial reductive dechlorination of trichloroethene to ethene with electrodes serving as electron donors without the external addition of redox mediators. Biotechnol Bioeng 103(1): 85-91.

6. Aulenta F, Canosa A, De Roma L, Reale P, Panero S, et al. (2009) Influence of mediator immobilization on the electrochemically assisted microbial dechlorination of trichloroethene (TCE) and cis-dichloroethene (cisDCE). J Chem Technol Biotechnol 84(6): 864-870.
7. Clauwaert P, Rabaey K, Aelterman P, de Schamphelaire L, Pham TH, et al. (2007) Biological denitrification in microbial fuel cells. Environ Sci Technol 41(9): 3354-3360.

8. Choi O, Sang BI (2016) Extracellular electron transfer from cathode to microbes: application for biofuel production. Biotechnol. Biofuels 9(1): 11.

9. Kumar G, Saratale RG, Kadier A, Sivagurunathan P, Zhen G, et al. (2017) A review on bio-electrochemical systems (BES) for the syngas and value added biochemicals production. Chemosphere 177: 84 -92.

10. Geppert F, Liu D, van Eerten-Jansen M, Weidner E, Buisman C, et al. (2016) Bioelectrochemical power to gas: State of the art and future perspectives. Trends Biotechnol 34(11): 879-894.

11. Cheng S, Logan BE (2007) Sustainable and efficient biohydrogen production via electro hydrogenesis. Proc Natl Acad Sci 104(47): 18871-18873.

12. Xafenian N, Mapelli V (2014) Performance and bacterial enrichment of bioelectrochemical systems during methane and acetate production. Int J Hydrogen Energy 39(36): 21864 - 21875.

13. Cheng S, Xing D, Call DF, Logan BE (2009) Direct biological conversion of electrical current into methane by electromethanogenesis. Environ Sci Technol 43(10): 3953 - 3958.

14. Kracke F, Vassilev I, Krömer JO (2015) Microbial electron transport and energy conservation - the foundation for optimizing bioelectrochemical systems. Front Microbiol 6: 575.

15. Patil SA, Hägerhäll C, Gorton L (2012) Electron transfer mechanisms between microorganisms and electrodes in bioelectrochemical systems. Bioanal Rev 4(2-4): 159-192.

16. Clauwaert P, Verstraete $W$ (2009) Methanogenesis in membraneless microbial electrolysis cells. Appl Microbiol Biotechnol 82(5): 829.

17. Villano M, Aulenta F, Ciucci C, Ferri T, Giuliano A, et al. (2010) Bioelectrochemical reduction of $\mathrm{CO}_{2}$ to $\mathrm{CH} 4$ via direct and indirect extracellular electron transfer by a hydrogenophilic methanogenic culture. Bioresource Technol 101(9): 3085-3090.

18. Mao X, Stenuit B, Polasko A, Alvarez-Cohen L (2015) Efficient metabolic exchange and electron transfer within a syntrophictrichloroethenedegrading coculture of Dehalococcoidesmccartyi 195 and Syntrophomonaswolfei. Appl Environ Microbiol 81(6): 2015-2024.

19. Lovley DR (2011) Reach out and touch someone: potential impact of DIET (direct interspecies energy transfer) on anaerobic biogeochemistry, bioremediation, and bioenergy. Rev Environ Sci Biotechnol 10: 101-105.

20. Shrestha PM, Rotaru AE, Aklujkar M, Liu F, Shrestha M, et al. (2013) Syntrophic growth with direct interspecies electron transfer as the primary mechanism for energy exchange. Environ Microbiol Rep 5(6): 904-910.

21. Rotaru AE, Shrestha PM, Liu F, Markovaite B, Chen, S, et al. (2014) Direct interspecies electron transfer between Geobactermetallireducens and Methanosarcinabarkeri. Appl Environ Microbiol 80: 4599-4605.

22. Rotaru AE, Shrestha PM, Liu FH, Shrestha M, Shrestha D, Embree M, et al. (2014) A new model for electron flow during anaerobic digestion: direct interspecies electron transfer to Methanosaeta for the reduction of carbon dioxide to methane. Energy Environ Sci 7(1): 408-415. 
Your next submission with JuniperPublishers will reach you the below assets

- Quality Editorial service

- Swift Peer Review

- Reprints availability

- E-prints Service

- Manuscript Podcast for convenient understanding

- Global attainment for your research

- Manuscript accessibility in different formats ( Pdf, E-pub, Full Text, audio)

- Unceasing customer service

Track the below URL for one-step submission https://juniperpublishers.com/online-submission.php 